\title{
Upwelling along the western coast of the Iberian Peninsula: dependence of trends on fitting strategy
}

\author{
F. Santos ${ }^{1, *}$, M. Gómez-Gesteiraa ${ }^{1}$, M. deCastro ${ }^{1}{ }^{1}$ I. Álvarez ${ }^{1,2}$ \\ ${ }^{1}$ EPHYSLAB (Environmental Physics Laboratory), Universidade de Vigo, Spain \\ ${ }^{2}$ Universidade de Aveiro, Departamento de Física, 3810-193 Aveiro, Portugal
}

\begin{abstract}
We investigated upwelling variability along the western coast of the Iberian Peninsula for the period 1948-2009 by means of wind data extracted from the NCEP/NCAR reanalysis project. According to most previous studies, a remarkable weakening in upwelling intensity has been observed in the area. However, the observed linear trends are highly dependent on the length of the series. Here we show how the upwelling index signal can be fitted to different functions with diametrically opposed results. Both a simple linear regression and the fit to an equation including a linear term and a sinusoid with periodicity of 10.9 yr show weakening of upwelling intensity. In contrast, the fit to a more complex function including a linear term and a double sinusoid with short and long periodicities of $T_{S}=10.9$ and $T_{l}=89 \mathrm{yr}$ show strengthening of upwelling intensity. Both periodicities can be related to the Schwabe and Gleissberg cycles of solar activity. Although this last function showed a greater significance than the others, some uncertainty remains in the actual duration of the long period due to the short length of the upwelling index signal.
\end{abstract}

KEY WORDS: Coastal upwelling · Trends · Natural variability

Resale or republication not permitted without written consent of the publishe

\section{INTRODUCTION}

Upwelling is an oceanographic phenomenon involving persistent upward motion of sea water toward the ocean surface, replacing the surface water which has moved away in a process called divergence. Different types of upwelling have been proposed depending on the nature of this divergence. Among them, coastal upwelling may be the best studied because of its economic importance. Coastal upwelling is mainly caused by the combination of 3 factors: (1) wind blowing in a persistent way, (2) the presence of a solid boundary, and (3) the Coriolis effect. For example, in the Northern Hemisphere, when winds blow equatorward along an eastern ocean boundary surface, waters are driven away from the coasts (Ekman transport) and replaced by denser water from below. In general, intermediate layers are rich in nutrients which are used by phytoplankton, along with dissolved $\mathrm{CO}_{2}$ and solar energy, to produce organic compounds through photosynthesis. Upwelling regions therefore result in very high primary productivity. Coastal upwelling is the basis for $20 \%$ of the global fish catch, although it constitutes
$<1 \%$ of the world's ocean by area (McGregor et al. 2007).

The western coast of the Iberian Peninsula (hereafter 'WIP') is the northern zone of the Canary Upwelling System, one of the 4 major upwelling regions in the world (Di Lorenzo 2003, Pelegri et al. 2005, Patti et al. 2008). Previous studies (Wooster et al. 1976, Fiuza 1983, Nykjaer \& Van Camp 1994, Peliz et al. 2002, Gómez-Gesteira et al. 2006, Relvas et al. 2007, Alvarez et al. 2008a,b, Herrera et al. 2008) have shown that seasonal upwelling activity mainly occurs during the spring-summer season along the WIP. Torres et al. (2003) stressed the high variability of the wind field in this region (i.e. observations at a single point, coastal or offshore, will not necessarily be representative of coastal conditions over a significant distance) and the absence of any clear seasonal cycle.

Upwelling trends and their relationship with climate change have remained an open question since the seminal paper of Bakun (1990), who examined the evolution of wind stress off California, the Iberian Peninsula, Canary region, and Peru for the period covering the mid-1940s to the mid-1980s. Wind stress increased at 
the 4 locations, although at different rates. State-space statistical models found increased coastal upwelling for the period 1945-1990 in the California Current system (Schwing \& Mendelssohn 1997) and in the California and Peru-Chile current systems (Mendelssohn \& Schwing 2002). A similar increase in alongshore wind stress was described by Di Lorenzo et al. (2005) in the California Current system. Finally, McGregor et al. (2007) also found evidence of increasing upwelling activity in the area near Cape Ghir in the Canary Upwelling System. Most of these observations are in good agreement with the mechanism described by Bakun (1990). According to this mechanism, when surface air temperature increases, a low-pressure center develops over land while a higher-pressure center develops over the slow-warming ocean waters with the coast acting as a boundary separating the 2 centers. This situation enhances northern winds favoring upwelling.

A different situation has been described by other authors along the WIP. Lemos \& Pires (2004) found evidence of a progressive weakening of the upwelling regime for the period 1941-2000 using 3 land stations close to the Portuguese coast. Alvarez et al. (2008a) did not observe a clear trend at a monthly scale, although on average, upwelling tended to decrease for the period 1967-2006. A decrease in upwelling index was also described by Pérez et al. (2010) at the northwestern corner of the Iberian Peninsula for the period 1965-2007. Pardo et al. (2011, this issue) extended their analysis to the evolution of upwelling intensity along the major upwelling systems of the world. Gómez-Gesteira et al. (2011, this issue) calculated the annual and seasonal upwelling index trends for the period 1975-2008 coinciding with the last warming period observed in the area around the Atlantic and Cantabrian part of the Iberian Peninsula (deCastro et al. 2009). They found a significant decrease for the region of Galicia-North Portugal.

Finally, at longer time scales, the intensification of upwelling in the Galician-Portuguese margin during approximately the last 1000 yr has been well described (Diz et al. 2002, Soares \& Dias 2006, Martins et al. 2006, 2007, Muñoz- Sobrino et al. 2007). Bernárdez et al. (2008) observed that the biosiliceous and geochemical signatures of sediments from the last $500 \mathrm{yr}$ indicate enhanced upwelling and increased phytoplanktonic production associated with the intensification of northerly winds.

The main goal of the present analysis was to describe the variability and trends in upwelling intensity from 1948-2009 along the WIP. Different fitting procedures, from the linear method to a model including a linear trend and several periodic modulations related to natural forcing, were considered. The results strongly depend on the fitting function.

\section{DATA AND METHODS}

Wind data were retrieved from the National Centers for Environmental Prediction/National Center for Atmospheric Research (NCEP/NCAR). Reanalysis data are available from 1948 onwards with global coverage and spatial resolution of $2.5 \times 2.5^{\circ}$ (Kalnay et al. 1996; www.esrl.noaa.gov/psd/data/reanalysis/reanalysis.sht $\mathrm{ml})$. Two points located in front of the WIP at $10^{\circ} \mathrm{W}$ and 40.0 and $42.5^{\circ} \mathrm{N}$, respectively, were considered in the present study, which covers the period 1948-2009. Although a third point is located along the WIP at $37.5^{\circ}$ $\mathrm{N}$, it is close to Cabo Sao Vicente, where the wind dynamics can change drastically due to topographical features. Thus, that point was discarded from the present analysis. Ekman transport was calculated from wind data following the expressions:

$$
\begin{aligned}
& Q_{\mathrm{x}}=\frac{\rho_{\mathrm{a}} C_{\mathrm{d}}}{\rho_{\mathrm{w}} f}\left(W_{\mathrm{x}}^{2}+W_{\mathrm{y}}^{2}\right)^{1 / 2} W_{\mathrm{y}} \\
& \text { and } \\
& Q_{\mathrm{y}}=-\frac{\rho_{\mathrm{a}} C_{\mathrm{d}}}{\rho_{\mathrm{w}} f}\left(W_{\mathrm{x}}^{2}+W_{\mathrm{y}}^{2}\right)^{1 / 2} W_{\mathrm{x}}
\end{aligned}
$$

where $W$ is wind speed near the surface $(0.995$ sigma level), $\rho_{\mathrm{w}}$ is the sea water density $\left(1025 \mathrm{~kg} \mathrm{~m}^{-3}\right), C_{\mathrm{d}}$ is a dimensionless drag coefficient $\left(1.4 \times 10^{-3}\right), \rho_{\mathrm{a}}$ is the air density $\left(1.22 \mathrm{~kg} \mathrm{~m}^{-3}\right), f$ is the Coriolis parameter, defined as twice the vertical component of the Earth's angular velocity, $\Omega$, about the local vertical given by $f=2 \Omega \sin (\theta)$ at latitude $\theta$. Finally, the subscripts $\mathrm{x}$ and $\mathrm{y}$ correspond to the zonal and meridional components, respectively. The upwelling index (UI, $\mathrm{m}^{3} \mathrm{~s}^{-1} \mathrm{~km}^{-1}$ ), calculated from wind data, can be defined as the fraction of the Ekman transport that is perpendicular to the coast (Bakun 1990, Nykjaer \& Van Camp 1994). This index is calculated as the component of Ekman transport perpendicularly to the shoreline by

$$
\mathrm{UI}=Q_{\perp}=-\sin (\theta) Q_{\mathrm{x}}+\cos (\theta) Q_{\mathrm{Y}}
$$

where $\theta=\pi / 2+\varphi$ and $\varphi$ is the angle of the unitary vector perpendicular to the shoreline pointing landward (Gómez-Gesteira et al. 2006). Positive (negative) UI values mean upwelling favorable (unfavorable) conditions.

Wind fields must be correlated for the calculation of the mean UI. The correlation between UI at both points was $r=0.85$, which allows considering a mean UI. Note that even though the points are located about $2.5^{\circ}$ apart, the WIP coast is practically perpendicular to the equator in such a way that UI does not show important meridional differences. In the present study, we considered that the averaged values are more reliable that those calculated at single points, since the gridded data can present biases that vary from point to point (see Josey et al. 2002).

The following methodology was applied: (1) UI was calculated from wind fields at the locations described 
above. (2) UI was meridionally and seasonally averaged using monthly values corresponding to the extended summer (April through September, following Nykjaer \& Van Camp 1994 and Alvarez et al. 2008a). (3) Seasonal data were smoothed with a $( \pm 2)$ running average filter centered in the year under study; this running average filters high-frequency oscillations in the signal which can mask long-term evolution. Here we refer to the signal that was filtered and averaged in space as $(\widetilde{U I})$.

The $\widetilde{U I}$ signal was analyzed by means of a Fast Fourier Transform (FFT) to determine its possible periodicities. A windowing technique (Press et al. 1992, Emery \& Thompson 2004) was used to detect the relevant frequencies with the highest accuracy. In some cases, the periodicity of the signal was too long to be detected by the FFT analysis. In those cases, a trial and error analysis was used to maximize the correlation between the real and the fitted function. The signal was fitted to a known frequency determined by the previous FFT analysis and to a lower (unknown) frequency. The significance of the correlation was calculated by means of Student's t-test. The original signal was filtered before calculation, which implies that the resulting degrees of freedom are fewer than the ones corresponding to the original signal. Thus, $\mathrm{N}$ being the number of samples and $\mathrm{n}$ the number of neighbors used in the running average filter $( \pm 2$ in the present study, which results in $\mathrm{n}=5$ ), the degrees of freedom were $N^{\prime}=N / \mathrm{n}$, which is the value that was used in the significance testing.

\section{RESULTS AND DISCUSSION}

A simple linear fitting similar to the ones described by Alvarez et al. (2008a) and Pérez et al. (2010) showed a decreasing trend in $\widetilde{U I}\left(-7.8 \mathrm{~m}^{3} \mathrm{~s}^{-1} \mathrm{~km}^{-1}\right.$ decade $\left.^{-1}\right)$, with a significance $<90 \%$ (Table 1 ). This decrease is considerably lower than the one observed by Pérez et al. (2010) $\left(\sim-45 \mathrm{~m}^{3} \mathrm{~s}^{-1} \mathrm{~km}^{-1}\right.$ decade $\left.{ }^{-1}\right)$. The discrepancy can be attributed to different factors. (1) Pérez et al. (2010) considered the period 1965-2007. (2) they only considered a single point from reanalysis located at the northwestern corner of the Iberian Peninsula $\left(42.85^{\circ} \mathrm{N}\right.$,

Table 1. Summary of fitting strategies. R: correlation coefficient; significance calculated with Student's $t$-test. Trends are in $\mathrm{m}^{3} \mathrm{~s}^{-1} \mathrm{~km}^{-1}$ decade ${ }^{-1}$. Periodicities: $T_{s}=10.9$ and $T_{l}=89 \mathrm{yr}$

\begin{tabular}{|lccc|}
\hline & $\mathrm{R}$ & $\mathrm{p}$ & Trend \\
\hline Linear function & 0.36 & $85 \%$ & -7.8 \\
Linear function and sinusoid $\left(T_{s}\right)$ & 0.53 & $95 \%$ & -8.5 \\
Linear function and double & 0.78 & $99 \%$ & 16.2 \\
sinusoid $\left(T_{s}, T_{l}\right)$ & & & \\
\hline
\end{tabular}

$\left.9.37^{\circ} \mathrm{W}\right)$; the validity of this point was corroborated with local data measured at $\left(43^{\circ} \mathrm{N}, 11^{\circ} \mathrm{W}\right)$. (3) Pérez et al. (2010) considered the evolution of annual UI instead of the evolution of seasonal UI. This approach can be misleading, since upwelling is a seasonal phenomenon, and a seasonal analysis is more suitable. Otherwise, the trend can be biased by changes in wind intensity and direction during the non-upwelling season. Lemos \& Pires (2004) and Alvarez et al. (2008a) also described high variability depending on the month under study.

Comparison with previous studies has shown that the observed trends are strongly dependent on the length of the time series, which indicates that the observed behavior is not linear. To investigate the multidecadal variability of upwelling, we calculated trends in groups of 21 yr. For each year, the trend was computed for itself and for the previous and following $10 \mathrm{yr}$, e.g. the trend for 1958 was computed for the sub-period 1948-1968 and so on. This period of $21 \mathrm{yr}$ is long enough to filter high-frequency variability but short enough to retain multidecadal oscillations. Fig. 1 shows the trends for the period 1958-1999, calculated from the raw signal without previous filtering. High variability was observed in both signals. Furthermore, the trend can be both positive and negative during the period under study, although the mean trend was negative $\left(-11.1 \mathrm{~m}^{3} \mathrm{~s}^{-1} \mathrm{~km}^{-1}\right.$ decade $\left.^{-1}\right)$. Note that this mean trend differs slightly from the one shown above $\left(-7.8 \mathrm{~m}^{3} \mathrm{~s}^{-1} \mathrm{~km}^{-1}\right.$ decade $\left.^{-1}\right)$, since the periods of study are different.

As previously mentioned, the $\widetilde{U I}$ signal is nonlinear, which makes it difficult to distinguish between changes due to natural variability and trends. The FFT analysis using a windowing technique shows a main peak between 10.7 and $12.8 \mathrm{yr}$. The length of the record only allows a coarse discretization in terms of frequency (period).

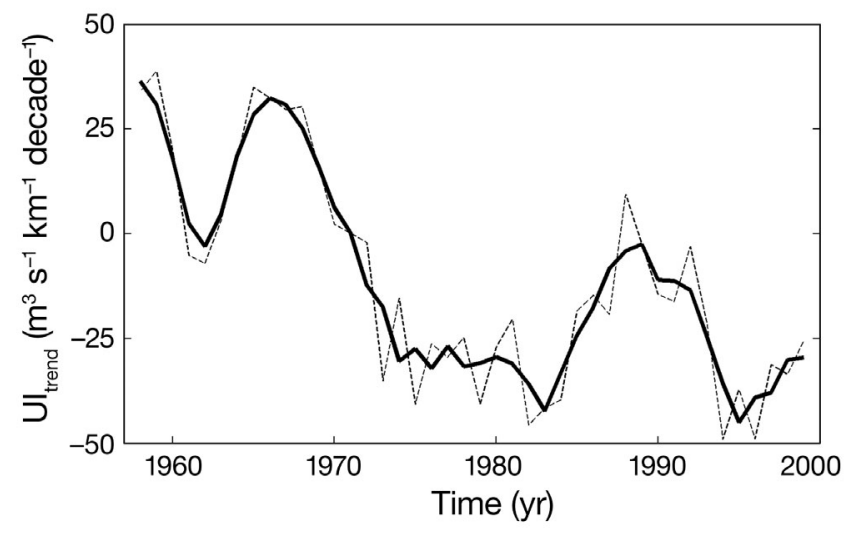

Fig. 1. Trends in upwelling index (UI) along the western coast of the Iberian Peninsula (WIP) for the period 1958-1999. Data were grouped in intervals of $21 \mathrm{yr}$ prior to linear fitting. The dashed line corresponds to the raw trends, and the solid line to the trends smoothed with a running average $( \pm 1 \mathrm{yr})$ 
This period is close to the Schwabe cycle of solar activity, which is $10.7 \mathrm{yr}$ (Usoskin et al. 2009). This fact does not necessarily suppose that changes in solar irradiance directly result in changes in wind (upwelling) patterns. Some authors (Haigh 1996, White et al. 1997) have proposed indirect mechanisms (cloud coverage, atmospheric wind) to link sea surface temperature to changes in solar irradiance. Thus, in the case of the UI, the changes can be modulated via changes in the teleconnection patterns (Barnston \& Livezey 1987, Hurrell 1995, deCastro et al. 2008). According to Stephenson et al. (2000), the North Atlantic Oscillation (NAO) also shows decadal variations that are unlikely to be obtained from sampling a white noise process. The most recent solar cycles were analyzed in an exploratory way to study their possible relationship with the peaks in the upwelling signal (solid line in Fig. 2). The last solar cycles ended in April 1954, October 1964, June 1976, September 1986, May 1996, and December 2008. On the other hand, peaks in the $\widetilde{U I}$ signal used were observed in 1955, 1963, 1974, 1989, 1996, and 2009. Thus the peaks in both signals do not exactly coincide, although they are relatively close. On average, the length of the last solar cycles (from the 1950s on) is 10.9 $\mathrm{yr}$, which is the periodicity that was considered in the present analysis.

$\widetilde{U I}$ can be fitted to a sinusoidal function with a possible linear trend following

$$
\widetilde{U I}=a+b t+c \cos \left(\frac{2 \pi}{T_{s}} t+\varphi_{s}\right)
$$

where $a, b, c$, and $\varphi_{s}$ are a set of unknowns to be computed, and time of the short period, $T_{s}=10.9 \mathrm{yr}$ is the imposed periodicity. This fitting shows a decreasing trend in $\widetilde{U I}\left(-8.5 \mathrm{~m}^{3} \mathrm{~s}^{-1} \mathrm{~km}^{-1} \mathrm{dec}^{-1}\right)$ with a significance of $95 \%$ (see Table 1). This value is close to the one calculated by simple linear fitting, albeit with a higher significance, since the sinusoidal part is able to reproduce

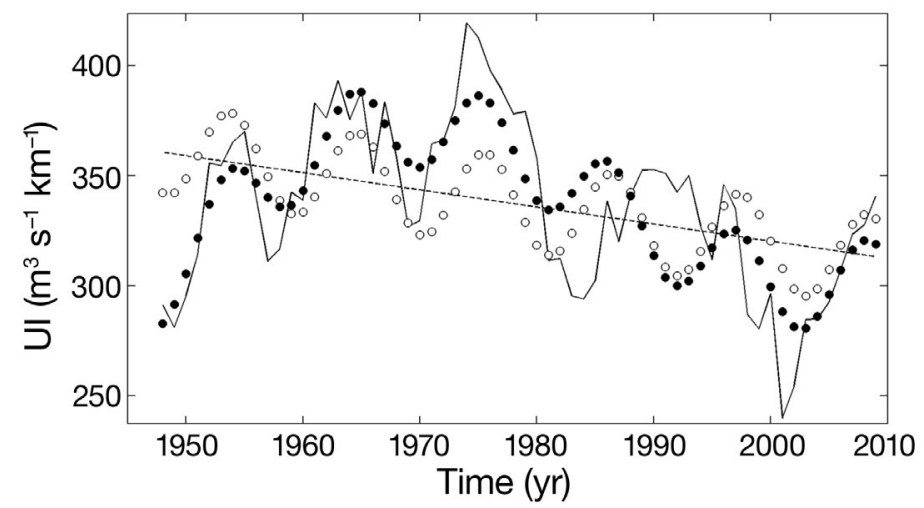

Fig. 2. Comparison between the upwelling index signal that was filtered and averaged in space ( $\widetilde{U I}$; solid line) and the different fitting functions. Linear (dashed line); linear and sinusoidal (open circles); linear and double sinusoid (closed circles) the decadal periodicity of the signal. Nevertheless, the different amplitude of the peaks cannot be satisfactorily reproduced assuming only periodicity.

The $\widetilde{U I}$ signal was then fitted to a double sinusoid with a possible linear trend following

$$
\widetilde{U I}=a+b t+c \cos \left(\frac{2 \pi}{T_{s}} t+\varphi_{s}\right)+d \cos \left(\frac{2 \pi}{T_{1}} t+\varphi_{1}\right)
$$

where $a, b, c, d, \varphi_{l}$, and $\varphi_{s}$ are a set of unknowns to be computed, and $T_{1}$ and $T_{s}$ represent the long and short period, respectively. Note that $T_{l}$ was not determined by the previous FFT analysis, due to the limited extent of the series, so its value was determined by computing the value of $T_{1}$ that provided the highest correlation coefficient (R) between $\widetilde{U I}$ and the fitted signal. The best estimate, $\mathrm{R}=0.78$ with a significance higher than $99 \%$, was obtained for $T_{1}=89 \mathrm{yr}$, considering $T_{S}=$ $10.9 \mathrm{yr}$ to be a constant. However, this fit does not result in a negative trend in $\widetilde{U I}$, but rather in a positive one $\left(16.2 \mathrm{~m}^{3} \mathrm{~s}^{-1} \mathrm{~km}^{-1} \mathrm{dec}^{-1}\right)$. This periodicity can be related to the Gleissberg cycle of solar activity, which is around 87 yr (70-100 yr; Peristykh \& Damon 2003, Braun et al. 2005). According to some authors (e.g. Yousef 2006), several prominent teleconnection patterns such as the NAO or El Niño Southern Oscillation, the levels of different lakes, and even fisheries can be influenced by this cycle. Finally, the trend is variable and our result cannot be considered an absolute value. Actually, any $T_{1}$ between 70 and $100 \mathrm{yr}$ resulted in a correlation coefficient similar to the one obtained for $T_{1}=89 \mathrm{yr}(1 \%$ lower at most $)$, although the trends ranged from 4 to $25 \mathrm{~m}^{3} \mathrm{~s}^{-1} \mathrm{~km}^{-1} \mathrm{dec}^{-1}$ and were always positive.

\section{SUMMARY}

The $\widetilde{U I}$ signal was fitted to different equations to analyze the variability in upwelling observed during the last decades. Both a simple linear fitting and a more complex, sinusoidal $\left(T_{s}=10.9 \mathrm{yr}\right)$ and linear fitting resulted in a negative trend in upwelling intensity. In contrast, the fit of the signal to a straight line and to a double sinusoid ( $T_{s}=10.9$ and $T_{1}=89 \mathrm{yr}$, respectively) resulted in a positive trend in upwelling intensity. This last fitting function provided the best estimate, with a significance $>99 \%$. Moreover, observed periodicities did not correspond to the mathematical values that maximized the correlation coefficient between $\widetilde{U I}$ and the fitting function, but rather coincided with periodicities in solar activity, the Schwabe and Gleissberg cycles.

The present study does not elucidate whether the long periodicity is real or a mathematical artifact. None of the approaches is comprehensive, since the linear 
assumption is too coarse and the single sinusoid does not explain the amplitude of the different peaks.

In summary, it is still unclear which part of the observed changes in coastal upwelling is related to natural causes and which part is linked to shifts with a possible anthropogenic cause.

Acknowledgements. This work was supported by the Ministerio de Ciencia e Innovación under the FEDER-funded project CTM2007-62546-C03-03/MAR and under project CGL200909143. We thank A. Ferriz-Mas for helpful discussions on solar cycles.

\section{LITERATURE CITED}

Alvarez I, Gómez-Gesteira M, deCastro M, Dias JM (2008a) Spatiotemporal evolution of upwelling regime along the western coast of the Iberian Peninsula. J Geophys Res 113: C07020 doi:10.1029/2008JC004744

- Alvarez I, Gómez-Gesteira M, deCastro M, Novoa EM (2008b) Ekman transport along the Galician Coast (NW Spain) calculated from QuikSCAT winds. J Mar Syst 72: 101-115 doi:10.1016/j.jmarsys.2007.01.013

Bakun A (1990) Global climate change and intensification of coastal upwelling. Science 247:198-201 doi:10.1126/science. 247.4939.198

Barnston AG, Livezey RE (1987) Classification, seasonality and persistence of low-frequency atmospheric circulation patterns. Mon Weather Rev 115:1083-1126

- Bernárdez P, González-Álvarez R, Francés G, Prego R, Bárcena MA, Romero OE (2008) Palaeoproductivity changes and upwelling variability in the Galicia Mud Patch during the last 5000 years: geochemical and microfloral evidence. Holocene 18:1207-1218 doi:10.1177/0959683608096596

Braun H, Christl M, Rahmstorf S, Ganopolski A and others (2005) Possible solar origin of the 1,470-year glacial climate cycle demonstrated in a coupled model. Nature 438: 208-211 doi:10.1038/nature04121

deCastro M, Gómez-Gesteira M, Lorenzo MN, Alvarez I, Crespo AJC (2008) Influence of atmospheric modes on coastal upwelling along the western coast of the Iberian Peninsula, 1985 to 2005. Clim Res 36:169-179 doi:10.3354/cr00742

> deCastro M, Gómez-Gesteira M, Alvarez I, Gesteira JLG (2009) Present warming within the context of coolingwarming cycles observed since 1854 in the Bay of Biscay. Cont Shelf Res 29:1053-1059

> Di Lorenzo E (2003) Seasonal dynamics of the surface circulation in the Southern California Current System. Deep Sea Res II 50:2371-2388

Di Lorenzo E, Miller AJ, Schneider N, McWilliams JC (2005) The warming of the California current system: dynamics and ecosystem implications. J Phys Oceanogr 35:336-362

Diz P, Francés G, Pelejero C, Grimalt JO, Vilas F (2002) The last 3000 years in the Ría de Vigo (NW Iberian Margin): climatic and hydrographic signals. Holocene 12: 459-468

Emery WJ, Thompson RE (2004) Data analysis methods in physical oceanography, 2nd edn. Elsevier, Amsterdam

Fiuza AFG (1983) Upwelling patterns off Portugal. In: Suess E, Thiede J (eds) Coastal upwelling: its sediment record. Plenum, New York, p 85-98

> Gómez-Gesteira M, Moreira C, Alvarez I, deCastro M (2006) Ekman transport along the Galician coast (northwest Spain) calculated from forecasted winds. J Geophys Res 111:C10005 doi:10.1029/2005TC003331
Gómez-Gesteira M, Gimeno L, deCastro M, Lorenzo MN and others (2011) The state of climate in NW Iberia. Clim Res 48:109-144

Haigh J (1996) On the impact of solar variability on climate. Science 272:981-984

- Herrera JL, Rosón G, Varela RA, Piedracoba S (2008) Variability of the western Galician upwelling system (NW Spain) during an intensively sampled annual cycle: an EOF analysis approach. J Mar Syst 72:200-217

Hurrell JW (1995) Decadal trends in the North Atlantic Oscillation: regional temperatures and precipitation. Science 269:676-679

Josey SA, Kent EC, Taylor PK (2002) Wind stress forcing of the ocean in the SOC climatology: comparisons with the NCEP-NCAR, ECMWF, UWM/COADS, and Hellerman and Rosenstein datasets. J Phys Oceanogr 32:1993-2019

Kalnay E, Kanamitsu M, Kistler R, Collins W and others (1996) The NCEP/NCAR 40-year reanalysis project. Bull Am Meteorol Soc 77:437-470

Lemos RT, Pires HO (2004) The upwelling regime off the west Portuguese coast, 1941-2000. Int J Climatol 24:511-524. doi:10.1002/joc.1009

Martins V, Jouanneau JM, Weber O, Rocha F (2006) Tracing the late Holocene evolution of the NW Iberian upwelling system. Mar Micropaleontol 59:35-55

Martins V, Dubert J, Jouanneau JM, Weber O and others (2007) A multiproxy approach of the Holocene evolution of shelf-slope circulation on the NW Iberian continental shelf. Mar Geol 239:1-18

McGregor HV, Dima M, Fischer HW, Mulitza S (2007) Rapid 20th-century increase in coastal upwelling off northwest Africa. Science 315:637-663 doi:10.1126/science.1134839

Mendelssohn R, Schwing FB (2002) Common and uncommon trends in SST and wind stress in the California and PeruChile current systems. Prog Oceanogr 53:141-162

Muñoz-Sobrino C, García-Gil S, Diez JB, Iglesias J (2007) Palynological characterization of gassy sediments in the inner part of Ría de Vigo (NW Spain). New chronological and environmental data. Geo-Mar Lett 27:289-302

- Nykjaer L, Van Camp L (1994) Seasonal and interannual variability of coastal upwelling along northwest Africa and Portugal from 1981 to 1991. J Geophys Res 99:14197-14208

> Pardo PC, Padín XA, Gilcoto M, Farina-Busto L, Pérez FF (2011) Evolution of upwelling systems coupled to the longterm variability in sea surface temperature and Ekman transport. Clim Res 48:231-246

Patti B, Guisande C, Vergara AR, Riveiro I and others (2008) Factors responsible for the differences in satellite-based chlorophyll a concentration between the four major global upwelling areas. Estuar Coast Shelf Sci 76:775-786 doi:10. 1016/j.ecss.2007.08.005

> Pelegri JL, Aristegui J, Cana L, Gonzalez-Davila M and others (2005) Coupling between the open ocean and the coastal upwelling region off northwest Africa: water recirculation and offshore pumping of organic matter. J Mar Syst 54:3-37

> Peliz A, Rosa TL, Santos AMP, Pissarra JL (2002) Fronts, jets and counter-flows in the Western Iberian upwelling system. J Mar Syst 35:61-77

Pérez FF, Padín XA, Pazos Y, Gilcoto M and others (2010) Plankton response to weakening of the Iberian coastal upwelling. Glob Change Biol 16:1258-1267 doi:10.1111/j. 1365-2486.2009.02125.x

> Peristykh AN, Damon PE (2003) Persistence of the Gleissberg 88-year solar cycle over the last 12,000 years: evidence from cosmogenic isotopes. J Geophys Res 108:1003 doi:10. 1029/2002JA009390

Press WH, Teukolsky SH, Vetterling WT, Flannery BP (1992) 
Numerical recipes in C: the art of scientific computing. Cambridge University Press, Cambridge

Relvas P, Barton ED, Dubert J, Oliveira PB, Peliz AJ, da Silva JC, Santos AMP (2007) Physical oceanography of the Western Iberia Ecosystem: latest views and challenges. Prog Oceanogr 74:149-173 doi:10.1016/j.pocean.2007.04.021

Schwing FB, Mendelssohn R (1997) Increased coastal upwelling in the California Current system. J Geophys Res 102:3421-3438

Soares AMM, Dias JA (2006) Coastal upwelling and radiocarbon-evidence for temporal fluctuations in ocean reservoir effect off Portugal during the Holocene. Radiocarbon 48:45-60

Stephenson DB, Pavan V, Bojariu R (2000) Is the North Atlantic Oscillation a random walk? Int J Climatol 20:1-18 Torres R, Barton ED, Miller P, Fanjul E (2003) Spatial patterns

Submitted: July 20, 2010; Accepted: November 2, 2011 of wind and sea surface temperature in the Galician upwelling region. J Geophys Res 108(C4):3130 doi:10. 1029/2002JC001361

Usoskin IG, Mursula K, Arlt R, Kovaltsov GA (2009) A solar cycle lost in 1793-1800: early sunspot observations resolve the old mystery. Astrophys J Lett 700:L154. doi:10.1088/ 0004-637X/700/2/L154

White WB, Lean J, Cayan DR, Dettinger MD (1997) A response of global upper ocean temperature to changing solar irradiance. J Geophys Res 102:3255-3266

Wooster WS, Bakun A, McLain DR (1976) The seasonal upwelling cycle along the eastern boundary of the North Atlantic. J Mar Res 34:131-141

Yousef SM (2006) 80-120 yr long-term solar induced effects on the earth, past and predictions. Phys Chem Earth 31: $113-122$

Proofs received from author(s): August 4, 2011 